Article

\title{
The Effect of Consumer Perception on Food Waste Behavior of Urban Households in China
}

\author{
Panpan Zhang ${ }^{1}$, Dan Zhang ${ }^{2, *}$ and Shengkui Cheng ${ }^{2}$ \\ 1 School of Economics and Trade, Henan University of Technology, Zhengzhou 450001, China; \\ panpandazhang@163.com \\ 2 Institute of Geographic Sciences and Natural Resources Research, Chinese Academy of Sciences, \\ Beijing 100101, China; chengsk@igsnrr.ac.cn \\ * Correspondence: zhangdan@igsnrr.ac.cn
}

Received: 1 June 2020; Accepted: 10 July 2020; Published: 15 July 2020

check for updates

\begin{abstract}
Food waste has become a global problem, causing widespread concern in all sectors of society. Many scholars and institutions have researched this issue from different perspectives, but theoretical and empirical research on food waste from the perspective of consumer perception is still limited. Therefore, this study constructs a theoretical framework based on food waste behavior of households and empirically analyzes the effect of consumer perception on food waste by 273 Chinese urban households eating at home. The reliable urban household food waste data are based on a combination of household questionnaire surveys, bookkeeping surveys, weighing surveys, and semi-structured interviews in 2018. The survey site is Zhengzhou City in Henan Province. The results show that the higher urban household consumer perception positive index, the smaller the amount of food waste per capita per meal, and the higher urban household consumer perception negative index, the greater the amount of food waste per capita per meal. These results suggest consumer perception affects urban household food waste behavior significantly. We need to encourage consumers to form a joint effort to change consumer perception about food waste in order to reducing food waste.
\end{abstract}

Keywords: food waste; consumer perception; urban household; eating at home; behavior

\section{Introduction}

Food waste is a global problem causing widespread concern. Globally, around one-third of the world's food produced for human consumption (about 1.3 billion tons) is wasted or lost per year [1]. Currently, food waste is widespread and since it is a burgeoning problem, it has been the subject of much research. Food waste has been studied in the United States [2], Switzerland [3], Finland [4], Germany [5], Spain [6] and China [7]. Food waste is a significant problem in China, where the food waste per capita per meal in 2015 is $79.52 \mathrm{~g}$ in the catering industry [8] and the annual food waste in 2009 is estimated to be around 120 million tons [9]. According to a report jointly issued by the World Wide Fund for Nature (WWF) and the Institute of Geographic Sciences and Natural Resources Research, Chinese Academy of Sciences (IGSNRR, CAS), food waste in the urban areas of China is around 17-18 million tons in 2015 alone, which is equivalent to $3 \%$ of the national food production [10].

Food waste means not only the waste of food itself, but also an inefficient and wasteful input of the water, land, and other resources needed to produce the food. Therefore, food waste not only consumes global resources [11-13], but also contributes to severe resource and environmental pressures [14-16]. Various resources are used for the production of food, so the waste of food also means the loss or waste of those input resources, like land resources and water resources. According to the Food and Agriculture Organization of the United Nations, global food waste means the opportunity loss of arable land, surface water, and carbon dioxide emissions. For instance, when converted into greenhouse 
gases, the food discarded annually by Finnish households is approximately equal to the annual carbon dioxide emissions of 100,000 cars [17]. Even today, more than 820 million people in the world are still hungry [18]. If food loss and waste reduction could be achieved, by redistribution of the wasted food and/or by utilizing scarce input resources effectively, it would gradually help to reduce the numbers of hunger-stricken people from a global perspective.

Food waste occurs in all stages of the food supply chain and around 35\% of the food loss and waste occur from the consumer side [19]. Household food waste accounts for the most significant part of total food waste in developed countries [20,21]. Globally, this part is expected to increase with growing middle classes in emerging countries [22]. For example, around 130 million kg of food waste is generated each year (23 kg per capita/year) by the household sector in Finland [17]. The annual average food waste of households is estimated to be $65.49 \mathrm{~kg}$ per capita in Hungary [21]. In Germany, household food waste accounts for a large share of total food waste [23]. In Tehran, every consumer in household wastes about $27.6 \mathrm{~kg}$ of edible food annually and about 25 million tons of food go wasted or lost in Iran [24]. Because of the importance attached to this issue, an increasing number of studies on household food waste have been published in recent years [25-30].

Generally, food waste at the consumer level is the result of consumer behavior, which is influenced by consumer perception. To reduce food waste, it is therefore necessary to develop a clear understanding of its root causes at the individual level [31]. Currently, the situation and causes of food waste are not entirely clear, as there is a lack of first-hand survey data. Over half of existing publications are based only on secondary data [32], which signals the data on food waste in existing publications are also inconsistent, and the estimated results are quite different. Further, few studies analyze the food waste behavior of households eating at home based on consumer perception. Consequently, based on the theory of allocation time proposed by Becker [33], this study attempts to construct food waste theoretical framework eating at home. Based on reliable food waste data from field surveys of urban households, the effect of consumer perception on food waste behavior of urban households eating at home is empirically and quantitatively analyzed. This study will help broaden food waste research and provide scientific support for food waste reduction.

\section{Theoretical Framework}

This study constructs a theoretical framework for the study of household food waste, based on a theory of allocation time proposed by Becker [33]. On this basis, the study analyzes the effect of consumer perception on the food waste behavior of urban households eating at home. The specific purpose of the theoretical framework deduction is to show that consumer perception is an important factor affecting food waste.

According to traditional and improved selection theories, households maximize their utility functions during meals. We define $U$ as the total utility of the household during the process of decision-making meal and dining at home. Based on the assumption of rational individual in economics, households should also maximize their total utility in the process of decision-making and eating. The maximum total utilities can be expressed as $U_{\max }$. According to the Becker model, households use their time and the products available in the market to produce basic products, which can be directly incorporated into the households' utility functions. Households are affected by consumer perception when producing basic products, therefore consumer perception should be included in a household's utility function. Consumer perception is indicated by the symbol $\delta$. We define $y$ as the basic commodity produced by household using time and market commodities. They include household food intake $x$ and household food waste w. During household decision-making meal and dining at home, the optimal combination of a household's products is selected to maximize the total utility of meals:

$$
\begin{gathered}
\mathrm{U}=\mathrm{U}\left(\mathrm{y}_{i}, \cdots, \mathrm{y}_{m} ; \delta\right) \\
\mathrm{y}_{i}=f_{i}\left(\mathrm{z}_{i}, \mathrm{~T}_{i}\right)
\end{gathered}
$$


where $\mathrm{y}$ is a function of market products and time and $\mathrm{y}_{i}$ represents the $i$-th basic commodity produced by the household's comprehensive use of time and market goods, $z_{i}$ represents the food raw materials purchased by the household from the market, and $T_{i}$ represents the household raw food materials used along with time to produce household basic commodities.

We define $x$ as the household's food intake, which affects its overall utility $U$, where $x$ belongs to $y$. Based on the basic attributes of urban households eating at home, the quantity of food prepared by urban households is greater than or equal to the expected food intake, that is, $\mathrm{y}_{i} \geq \mathrm{E}\left(\mathrm{x}_{i}\right)$. The utility of these urban households can be divided into the utility from simple food intake by household members and the utility from food waste in the household.

We define $U_{\text {eat }}$ as the utility derived from simple food intake by household members. Its effect is based on the physiological functions of urban households. When household members have dining needs, this variable measures the effect of the simple food intake on them. $U_{\text {eat }}$ is generally affected by both household food intake and the consumer perception of household, which is expressed as:

$$
\mathrm{U}_{\text {eat }}=\mathrm{U}\left(\mathrm{x}_{i}, \cdots, \mathrm{x}_{m} ; \delta\right)
$$

Due to the physiological limits of food being consumed by household members and the assumption of economic rationality, the total utility of household meals should be maximized so there is a maximum household food intake during meals. The utility from simple food intake $U_{\text {eat }}$, for household members should meet the following conditions:

$$
\lim _{\mathrm{x}_{i} \rightarrow 0^{+}} \partial \mathrm{U}_{\text {eat }} / \partial \mathrm{x}_{i}>0 \text { and } \lim _{\mathrm{x}_{i} \rightarrow 0^{+}} \partial^{2} \mathrm{U}_{\text {eat }} / \partial \mathrm{x}_{i}^{2}<0
$$

The utility from food intake by household members first increases and then decreases, and its marginal effect is decreasing. If there exists $x_{i}^{\alpha}$ so that $\partial \mathrm{U}_{\text {eat }} / \partial \mathrm{x}_{i}=0$, the utility from simple food intake for household members begins to decline, $\partial \mathrm{U}_{\text {eat }} / \partial \mathrm{x}_{i}<0$.

As rational individuals, when household members eat $x_{i}^{\alpha}$, their simple food intake has the greatest utility. If $x_{i}^{\alpha}<y_{i}$ exists at this time, there is a waste of food in the household. If we define $\mathrm{w}_{i}$ as the amount of food waste in the household, then:

$$
\mathrm{w}_{i}=\mathrm{y}_{i}-\mathrm{x}_{i}^{\alpha}
$$

At this time, household utility comes from two aspects: The utility from food consumption for household members and the utility from food waste for household members.

We define $U_{\text {waste }}$ as the effect of food waste on households. The $w$ is the amount of food wasted by the household and $U_{\text {waste }}$ is part of the overall utility $U$. $U_{\text {waste }}$ is affected bythe amount of household food waste and the consumer perception of household food consumption. Its formula is as follows:

$$
\mathrm{U}_{\text {waste }}=\mathrm{U}\left(\mathrm{w}_{i}, \cdots, \mathrm{w}_{m} ; \delta\right)
$$

We define $x_{i}^{*}$ as the household's optimal amount of meals to maximize the total utility of the household dining at home, $\mathrm{U}_{\max }$. When the problem of food waste has no effect on the household, that is, when the household's perception level of food waste is zero $(\delta=0)$, the household can maximize its effect by adjusting the amount of food consumed. When the amount of household meals reaches $x_{i}^{\alpha}$, their utility is maximum. At this time, there exists $x_{i}^{*}=x_{i}^{\alpha}$.

When the problem of food waste has a negative effect on the household, the household has two ways to compensate for the negative effect. The first is when the household controls the number of prepared meals, $\mathrm{y}_{i}$, so that a small amount of food is prepared to prevent waste; the second is when the number of prepared meals is greater than the amount of the meals, meaning that the household reduces food waste by increasing meal amounts. 
In the first case, $\mathrm{y}_{i} \leq \mathrm{x}_{i}^{\alpha}$, and when $\mathrm{y}_{i} \leq \mathrm{x}_{i}^{*}$, then the household consumes all the prepared food and there is no food waste.

In the second case, $\mathrm{y}_{i}>\mathrm{x}_{i}^{\alpha}$, and when $\mathrm{y}_{i}>\mathrm{x}_{i}^{*}$, the household will reduce food waste by increasing the size of meals and maximize its utility. The $x_{i}^{*}$ is the optimal meal quantity. When $x_{i}^{*}<x_{i}<y_{i}$, if the household chooses to increase the amount of meals to reduce food waste, the increased meals, $\Delta \mathrm{x}_{i}=\mathrm{x}_{i}-\mathrm{x}_{i}^{*}$, will have negative effects on the household (e.g., physical discomfort). At this time, the amount of food waste in the household will also change due to changes in the amount of meals. As households seek to maximize the utility of their own meals, when a household chooses to increase the amount of meals to reduce food waste, the changes in its utility come from two aspects: The first is the decline in the utility caused by increased meals and the second is the increase in utility caused by waste reduction. When the marginal increase and decrease of the household meal utility are equal, the meal amount is the optimal meal amount of the household.

In the first case, the utility level is less than the utility level of the optimal meal amount, indicating that there is a loss of utility. In the second case, since the actual amount of meals is greater than the optimal amount and a certain amount of food waste is generated, the utility level is less than the utility level of the optimal meal, meaning that there is a loss of utility. Rationally, households will choose the lower utility loss.

Function y shows that the household is not only a unit of utility maximization, but also a unit of production. The household comprehensively uses time and market products to produce the basic product $\mathrm{y}_{i}$ through production function $\mathrm{y}$, and selects the optimal combination of household products to maximize this utility function. Household needs raw materials and time to prepare food so the household meals are maximized also constrained by commodities and time.

$$
\sum_{1}^{\mathrm{m}} \mathrm{p}_{i} \mathrm{x}_{i}+\sum_{1}^{\mathrm{m}} \mathrm{p}_{i} \mathrm{w}_{i}=\mathrm{I}_{\text {food }}=\mathrm{V}+\mathrm{T}_{l} \cdot l-\mathrm{I}_{\text {unfood }}
$$

where $\mathrm{p}_{i}$ represents the unit price vector of $\mathrm{y}_{i}$ (i.e., $\mathrm{x}_{i}$ and $\mathrm{w}_{i}$ ), $\mathrm{T}_{l}$ represents the time vector for work, $l$ represents the remuneration per unit of $\mathrm{T}_{l}, \mathrm{~V}$ represents other income, $\mathrm{I}_{\text {food }}$ represents the total household expenditure on food, and $\mathrm{I}_{\text {unfood }}$ represents the total non-food expenditure of household.

The time constraints for maximizing the utility of household meals are:

$$
\sum_{1}^{\mathrm{m}} \mathrm{T}_{i}=\mathrm{T}_{\text {food }}=\mathrm{T}-\mathrm{T}_{l}-\mathrm{T}_{\text {unfood }}
$$

where $\mathrm{T}$ represents the total amount of time available, $\mathrm{T}_{\text {food }}$ is the time vector used by the household for food consumption, and $\mathrm{T}_{\text {unfood }}$ is the time vector for activities other than the working and the consumption of food.

Time vector $\mathrm{T}_{l}$, which represents the time constraint used for work, is included into the commodity constraint and a single constraint is obtained as follows:

$$
\sum_{1}^{\mathrm{m}} \mathrm{p}_{i} \mathrm{x}_{i}+\sum_{1}^{\mathrm{m}} \mathrm{p}_{i} \mathrm{w}_{i}=\mathrm{I}_{\text {food }}=\mathrm{V}+\left(\mathrm{T}-\mathrm{T}_{\text {food }}-\mathrm{T}_{\text {unfood }}\right) \cdot l-\mathrm{I}_{\text {unfood }}
$$

According to the utility function and constraints of household dining, the Lagrangian function is constructed as:

$$
L=\mathrm{U}\left(\mathrm{x}_{i}, \cdots, \mathrm{x}_{m} ; \delta\right)+\mathrm{U}\left(\mathrm{w}_{i}, \cdots, \mathrm{w}_{m} ; \delta\right)+\gamma\left[\mathrm{V}+\left(\mathrm{T}-\mathrm{T}_{\text {food }}-\mathrm{T}_{\text {unfood }}\right)-\mathrm{I}_{\text {unfood }}-\mathrm{I}_{\text {food }}\right]
$$

By maximizing the condition of the utility function, we get:

$$
\mathrm{x}^{*}=\mathrm{x}(\mathrm{p}, 1, \mathrm{v}, \mathrm{T}, \delta)
$$




$$
\mathrm{w}^{*}=\mathrm{w}(\mathrm{p}, 1, \mathrm{v}, \mathrm{T}, \delta)
$$

That is,

$$
\left(\mathrm{x}^{*}, \mathrm{w}^{*}\right)=\mathrm{f}(\mathrm{p}, \mathrm{l}, \mathrm{v}, \mathrm{T}, \delta)
$$

Then, $\frac{\partial w^{*}}{\partial \delta}$ is the effect of consumer perception on household food waste behavior when eating at home. It should be pointed out that consumer perception is reflected by the consumer perception positive and negative indexes. Consumer perception positive index refers to a series of factors that can promote consumers to reduce food waste. Consumer perception negative index refers to a series of factors that cause consumers food waste.

\section{Materials and Method}

\subsection{Data Collection}

The urban household food waste data were based on combination of household questionnaire surveys, bookkeeping surveys, weighing surveys, and semi-structured interviews. Stratified random sampling is used to obtain the urban household food waste sample. The surveyed site is Zhengzhou City, Henan Province and the surveys take place from April to May in 2018. First of all, according to the ranking of per capita disposable income of urban residents in Zhengzhou, municipal districts of Zhengzhou were divided into three levels, from which Jinshui District, Erqi District, and Huiji District were randomly selected as research areas, and the sample size of each district was determined according to the proportion of households in each urban area. Secondly, based on the level of community development in each research area, the communities in the research area were divided into high, medium, and low levels, and sample communities were randomly selected from the communities with different levels. Finally, several residential areas were randomly selected from each sample community, and the sample households are determined according to the principle of equal distant sampling based on the household register of the residential area.

There was a total of 309 households that participated in the survey and 273 households completed the questionnaires and provided reliable data at a response rate of $88.35 \%$. Table 1 shows the surveyed areas. Each household was followed-up for three consecutive days. Due to the differences in food consumption and waste behaviors between weekdays and weekends, the three consecutive days included two consecutive weekdays and one weekend day. Specifically, the investigator visited the household every day to obtain its food waste data by weighing and recording the edible food discarded by the household during meals and the food discarded due to expiry or deterioration. Uniform electronic scales are used to weigh the waste materials. The unit of measurement of the electronic scales was grams and the maximum load was $5 \mathrm{~kg}$.

Table 1. Survey areas of urban household food waste in 2018.

\begin{tabular}{cccc}
\hline Survey Time & Survey City & Survey Area & Sample Size \\
\hline \multirow{2}{*}{2018} & \multirow{3}{*}{ Zhengzhou } & Jinshui District & 150 \\
& & Huiji District & 33 \\
Total & & Erqi District & 90 \\
& & & 273 \\
\hline
\end{tabular}

\subsection{Empirical Analysis}

This study uses the amount of food waste per capita per meal of urban households eating at home as dependent variable to empirically analyze the food waste behavior of urban households eating at home. Since part of food waste per capita per meal data of the respondents is equal to 0 , a Tobit model is adopted to overcome the data interception of the dependent variable. This model is considered that the dependent variable has a lower limit, and the upper limit or the existence of the limit value has 
already received extensive attention in the academic community. This model is a restricted dependent variable model in which the explanatory variable is not only continuous, but also tailed.

We define $y^{*}$ as a continuous random variable representing the amount of food waste per capita per meal of urban households. Only when $\mathrm{y}^{*}$ is greater than 0 , is $y=y^{*}$. When $\mathrm{y}^{*}$ is less than or equal to $0, y=0$. At the same time, a series of exogenous variables $\mathbf{x}$ is chosen to explain the behavior of $y$. In this way, the standard Tobit model is formed.

$$
\begin{gathered}
y_{i}^{*}=x_{i}^{\prime} \beta+\varepsilon_{i} i=1,2, \cdots, N, \varepsilon_{i} \sim N\left(0, \sigma^{2}\right) \\
y_{i}=\left\{\begin{array}{cc}
y_{i}^{*}, & \text { when } y_{i}^{*}>0 \\
0, & \text { when } y_{i}^{*} \leq 0
\end{array}\right.
\end{gathered}
$$

where $\beta$ reflects the effect of $x$ on $y^{*}$, not on $y$.

At this point, the likelihood function expression for this model is as follows:

$$
L\left(\beta, \sigma \mid y_{i}, \mathbf{x}_{i}\right)=\prod_{y_{i}=0} F\left(\frac{-\mathbf{x}_{i} \boldsymbol{\beta}}{\sigma}\right) \prod_{y_{i}>0} \frac{1}{\sigma} f\left(\frac{y_{i}-\mathbf{x}_{i} \boldsymbol{\beta}}{\sigma}\right)
$$

In the above formula, $\mathrm{F}$ and $\mathrm{f}$ are the distribution and density functions of the standard normal distribution, respectively. The log-likelihood function of this model is as follows:

$$
\operatorname{In} L\left(\beta, \sigma \mid y_{\mathrm{i}^{\prime}}, \mathbf{x}_{\mathrm{i}}\right)=\sum_{\mathrm{y}_{\mathrm{i}}=0} \operatorname{In}\left[1-\Phi\left(\frac{-\mathbf{x}_{\mathrm{i}} \boldsymbol{\beta}}{\sigma}\right)\right]+\sum_{\mathrm{y}_{\mathrm{i}}>0}\left[-\frac{1}{2}\left(\operatorname{In}(2 \pi)+\operatorname{In} \sigma^{2}+\frac{\left(\mathrm{y}_{\mathrm{i}}-\mathbf{x}_{\mathrm{i}} \boldsymbol{\beta}\right)^{2}}{\sigma^{2}}\right)\right]
$$

In this model, $y_{i}$ represents the amount of food waste per capita per meal of the $i$-th sample and $x_{i}$ represents the factors that affect food waste. In this study, we focus on analyzing the effect of consumer perception on food waste behavior.

\subsection{Main Variables}

The food waste measured in this study is the edible and non-liquid portion of the residual food. Inedible constituents of the food surplus like excipients, bones, and liquids are excluded. Because during the cooking process, food may absorb water, dehydrate, or absorb fat, we convert the measured weight of waste into the weight of food raw materials. Urban household consumer perception is

\begin{tabular}{|c|c|c|}
\hline Variable Name & Variable Description & Variable Value \\
\hline pw & $\begin{array}{l}\text { Food waste per capita per meal in the surveyed } \\
\text { households over three consecutive days }\end{array}$ & $\begin{array}{l}\text { Food waste per capita per meal in the surveyed } \\
\text { households over three consecutive days in grams. }\end{array}$ \\
\hline positive index & $\begin{array}{c}\text { Consumer perception positive index. It consists } \\
\text { of } 10 \text { survey questions that can promote } \\
\text { consumers to reduce food waste }\end{array}$ & $\begin{array}{l}\text { Values: } 0-50 \text {. The larger the value, the higher the } \\
\text { consumer's perception about reducing food waste }\end{array}$ \\
\hline negative index & $\begin{array}{l}\text { Consumer perception negative index. It consists } \\
\text { of } 10 \text { survey questions that can cause consumers } \\
\text { waste food. }\end{array}$ & $\begin{array}{l}\text { Values: } 0-50 \text {. The larger the value, the lower the } \\
\text { consumer's perception about reducing food waste }\end{array}$ \\
\hline gender & The gender of the respondents & 1 for male and 0 for female \\
\hline age & The age of the respondents & The age of respondents in years \\
\hline marriage & Marital status of respondents & \\
\hline unmarried & Whether the respondents are unmarried & $\begin{array}{c}1 \text { for unmarried respondents, and } 0 \text { otherwise } \\
\text { (reference group) }\end{array}$ \\
\hline married & Whether the respondents are married & 1 for married, and 0 otherwise \\
\hline divorce & Whether the respondents are divorced & 1 for divorced, and 0 otherwise \\
\hline widowed & Whether the respondents are widowed & 1 for widowed, and 0 otherwise \\
\hline
\end{tabular}
reflected by the urban household consumer perception index, which consists of the positive and negative consumer perception index. Definitions of the main variables are shown in Table 2.

Table 2. Variable definitions. 
Table 2. Cont

\begin{tabular}{|c|c|c|}
\hline Variable Name & Variable Description & Variable Value \\
\hline edu & The education level of the respondents & $\begin{array}{l}\text { The range of values is 1-8: } 1 \text { (never attended school); } \\
2 \text { (primary); } 3 \text { (junior high school); } 4 \text { (high school); } \\
5 \text { (junior college);6 (university); } 7 \text { (master); } 8 \text { (doctor) }\end{array}$ \\
\hline farmer & $\begin{array}{l}\text { Whether the respondents have } \\
\text { farming experience }\end{array}$ & 1 for farming experience, and 0 otherwise \\
\hline employ & The employment of respondents & \\
\hline full-time job & Whether respondents have full-time jobs & 1 for full-time job, and 0 otherwise \\
\hline part-time job & Whether respondents have part-time jobs & 1 for part-time job, and 0 otherwise \\
\hline unemployed & Whether respondents are unemployed & 1 for unemployed, and 0 otherwise \\
\hline retirement & Whether respondents are retired & 1 for retired, and 0 otherwise \\
\hline housework & Whether respondents are homemakers & 1 for homemakers, and 0 otherwise (reference group) \\
\hline odd jobs & Whether respondents only perform odd jobs & $\begin{array}{c}1 \text { if the respondent is accepting odd jobs, } \\
\text { and } 0 \text { otherwise }\end{array}$ \\
\hline other & Any other employment status of respondents & 1 for other employment, and 0 otherwise \\
\hline pincomem & $\begin{array}{l}\text { The monthly income level per capita of } \\
\text { the household }\end{array}$ & $\begin{array}{l}\text { The range of value is 1-8: } 1 \text { (under } 2000 \mathrm{RMB}) ; \\
\text { 2(2001-4000 RMB); 3(4001-6000 RMB); } \\
4(6001-8000 \mathrm{RMB}) ; 5(8001-10,000 \mathrm{RMB}) ; \\
6(10,001-12,000 \mathrm{RMB}) ; 7(12,001-14,000 \mathrm{RMB}) ; \\
\text { 8(above 14,000 RMB) }\end{array}$ \\
\hline animal & Whether the households have pets & 1 if the households have pets, and 0 otherwise \\
\hline cooker & Whether the respondents are actively cooking & 1 if the respondent cooks, and 0 otherwise \\
\hline info_fre & $\begin{array}{l}\text { Whether the respondent noticed food waste in } \\
\text { the past } 3 \text { months }\end{array}$ & 1 if the respondent noticed, and 0 otherwise \\
\hline refri_num & $\begin{array}{l}\text { The number of refrigerators owned by } \\
\text { the households }\end{array}$ & $\begin{array}{c}\text { The range of value is } 0 \text { to } n \text {, meaning: } \\
0 \text { (the household has no refrigerator); } 1 \text { (the household } \\
\text { has one refrigerators); } \mathrm{n} \text { (the household has } \\
\mathrm{n} \text { refrigerators) }\end{array}$ \\
\hline struct & The structure of the household & $\begin{array}{l}\text { The range of value is } 1 \text { to } n \text {, meaning: } \\
\text { 1(the household includes one generation); } \\
\text { 2(the household includes two generations); } \\
\text { n(the household includes n generations) }\end{array}$ \\
\hline count_p & Research regions & \\
\hline huiji & Whether the survey region is Huiji & 1 for Huiji, and 0 otherwise (reference group) \\
\hline erqi & Whether the survey region is Erqi & 1 for Erqi, and 0 otherwise \\
\hline jinshui & Whether the survey region is Jinshui & 1 for Jinshui, and 0 otherwise \\
\hline
\end{tabular}

The consumer perception positive index consists of 10 survey questions, as does the negative index. Values assigned to each reply are in the number sequence from five to one, where five represents strong agreement and one represents strong disagreement. The questions of the positive and negative perception indexes are shown in Tables 3 and 4, respectively.

Table 3. Questions of the consumer perception positive index.

\begin{tabular}{|c|c|c|c|c|c|}
\hline Questions & Options (Value & $5 / 4 / 3 / 2 / 1)$ & & & \\
\hline $\begin{array}{l}\text { The refrigerator is a good tool for storing food. Putting food } \\
\text { in the refrigerator can delay deterioration of the food }\end{array}$ & Strongly agree & Agree & General & Disagree & Strongly disagree \\
\hline I know exactly what food and ingredients are left at home & Strongly agree & Agree & General & Disagree & Strongly disagree \\
\hline I will consciously try to avoid leftovers when cooking & Every time & Often & Not often & Rarely & Never \\
\hline $\begin{array}{l}\text { After you put the unfinished food in the refrigerator, you will } \\
\text { eat it again }\end{array}$ & Every time & Often & Not often & Rarely & Never \\
\hline $\begin{array}{l}\text { Food waste means not only the waste of food itself, but also } \\
\text { waste of the inputs of water, land, and other resources needed } \\
\text { to produce the food }\end{array}$ & Strongly agree & Agree & General & Disagree & Strongly disagree \\
\hline $\begin{array}{l}\text { I would like to do less or eat monotonously in order to avoid } \\
\text { food waste }\end{array}$ & Strongly agree & Agree & General & Disagree & Strongly disagree \\
\hline I don't think we should store too much food at home & Strongly agree & Agree & General & Disagree & Strongly disagree \\
\hline I can quickly master tips for handling and storing food & Every time & Often & Not often & Rarely & Never \\
\hline Food waste behavior is absolutely not allowed in my family & Every time & Often & Not often & Rarely & Never \\
\hline $\begin{array}{l}\text { The ability of rational utilization of leftovers is insufficient, } \\
\text { and the leftovers should be minimized }\end{array}$ & Every time & Often & Not often & Rarely & Never \\
\hline
\end{tabular}


Table 4. Questions of the consumer perception negative index.

\begin{tabular}{|c|c|c|c|c|c|}
\hline \multirow{2}{*}{$\begin{array}{l}\text { Questions } \\
\text { You habitually throw away the skin or vegetable leaves of edible food }\end{array}$} & \multicolumn{5}{|c|}{ Options (Values: $5 / 4 / 3 / 2 / 1$ ) } \\
\hline & Strongly agree & Agree & General & Disagree & Strongly disagree \\
\hline $\begin{array}{l}\text { I find it difficult to estimate the amount of food the whole family needs to eat } \\
\text { each week }\end{array}$ & Strongly agree & Agree & General & Disagree & Strongly disagree \\
\hline While shopping, I will buy some food that I didn't intend to buy & Every time & Often & Not often & Rarely & Never \\
\hline If you encounter food you don't like, you will throw it away & Every time & Often & Not often & Rarely & Never \\
\hline $\begin{array}{l}\text { Sometimes even though I have prepared the ingredients, I will give up my } \\
\text { plan to cook because I am tired }\end{array}$ & Every time & Often & Not often & Rarely & Never \\
\hline I think that food waste is my own business and has nothing to do with others & Strongly agree & Agree & General & Disagree & Strongly disagree \\
\hline I like to cook more every time & Every time & Often & Not often & Rarely & Never \\
\hline $\begin{array}{l}\text { As far as Chinese food culture and habits are concerned, it is recognized and } \\
\text { acceptable to have leftovers }\end{array}$ & Every time & Often & Not often & Rarely & Never \\
\hline
\end{tabular}

\section{Results}

\subsection{Data Description}

The overall per capita per meal food waste in urban households is shown in Table 5. This study divided food into eight categories: Staples, meat (including aquatic products), vegetables, soybeans and their byproducts, eggs, dairy products, dried fruits/nuts, and fruit. The per capita per meal food waste of urban households eating at home was $5.54 \mathrm{~g}$, including per capita per meal waste of $1.04 \mathrm{~g}$ of staple products, $0.83 \mathrm{~g}$ of meat (including aquatic products), $2.60 \mathrm{~g}$ of vegetables, $0.05 \mathrm{~g}$ of soybeans and their byproducts, $0.13 \mathrm{~g}$ of eggs, $0.46 \mathrm{~g}$ of dairy products, $0.04 \mathrm{~g}$ of dried fruits/nuts, and $0.39 \mathrm{~g}$ of fruit.

Table 5. Food waste per capita per meal in urban households.

\begin{tabular}{cccccc}
\hline Variable & Mean & Std. Dev. & Min & Max & Percentage \\
\hline staple & 1.038 & 5.052 & 0.000 & 71.688 & $18.75 \%$ \\
meat & 0.832 & 3.978 & 0.000 & 51.014 & $15.02 \%$ \\
vegetables & 2.600 & 8.163 & 0.000 & 73.872 & $46.97 \%$ \\
soybeans & 0.048 & 0.243 & 0.000 & 2.381 & $0.87 \%$ \\
eggs & 0.129 & 0.808 & 0.000 & 7.154 & $2.33 \%$ \\
dairy products & 0.462 & 5.488 & 0.000 & 75.000 & $8.35 \%$ \\
dried fruits/nuts & 0.035 & 0.446 & 0.000 & 7.125 & $0.63 \%$ \\
fruit & 0.392 & 4.271 & 0.000 & 64.167 & $7.07 \%$ \\
\hline
\end{tabular}

Notes: The meat in the table included aquatic products. The soybeans in the table included soybeans and their byproducts.

The percentage of vegetables waste per capita per meal in urban households was as high as $46.97 \%$, while the percentage of staple waste per capita per meal in urban households was $18.75 \%$. Further, the percentage of meat (including aquatic products) waste was $15.02 \%$, that of dairy products was $8.35 \%$, and that of fruits was $7.07 \%$. The percentages of eggs, soybeans and their byproducts, and dried fruits/nuts waste per capita per meal in urban households accounted for a relatively small proportion.

\subsection{Descriptive Statistics}

The descriptive statistics of the main variables are shown in Table 6. The amount of food waste per capita per meal of urban households eating at home in China was $5.54 \mathrm{~g}$. The minimum value of the consumer perception positive index of urban households was 24 and the maximum was 49; the minimum value of the consumer perception negative index of urban households was 16 and the maximum was 45 . The sample size was 273 . 
Table 6. Descriptive statistics.

\begin{tabular}{|c|c|c|c|c|}
\hline Variable Name & Mean & Std. Dev. & Min & Max \\
\hline pw & 5.536 & 16.132 & 0 & 155.788 \\
\hline positive index & 38.659 & 4.310 & 24 & 49 \\
\hline negative index & 28.799 & 5.422 & 16 & 45 \\
\hline gender & 0.212 & 0.410 & 0 & 1 \\
\hline age & 50.637 & 14.439 & 20 & 80 \\
\hline \multicolumn{5}{|l|}{ marriage } \\
\hline unmarried & 0.029 & 0.169 & 0 & 1 \\
\hline married & 0.901 & 0.299 & 0 & 1 \\
\hline divorce & 0.015 & 0.120 & 0 & 1 \\
\hline widowed & 0.055 & 0.228 & 0 & 1 \\
\hline edu & 4.223 & 1.149 & 1 & 7 \\
\hline $\begin{array}{l}\text { farmer } \\
\text { employ }\end{array}$ & 0.484 & 0.501 & 0 & 1 \\
\hline full-time job & 0.355 & 0.479 & 0 & 1 \\
\hline part-time job & 0.029 & 0.169 & 0 & 1 \\
\hline unemployed & 0.033 & 0.179 & 0 & 1 \\
\hline retirement & 0.407 & 0.492 & 0 & 1 \\
\hline housework & 0.117 & 0.322 & 0 & 1 \\
\hline odd jobs & 0.018 & 0.134 & 0 & 1 \\
\hline other & 0.040 & 0.197 & 0 & 1 \\
\hline pincomem & 2.194 & 0.897 & 1 & 6 \\
\hline animal & 0.114 & 0.318 & 0 & 1 \\
\hline cooker & 0.788 & 0.410 & 0 & 1 \\
\hline info_fre & 2.542 & 1.124 & 1 & 5 \\
\hline refri_num & 1.121 & 0.388 & 0 & 3 \\
\hline $\begin{array}{l}\text { struct } \\
\text { count_p }\end{array}$ & 2.033 & 0.655 & 1 & 3 \\
\hline huiji & 0.121 & 0.327 & 0 & 1 \\
\hline erqi & 0.330 & 0.471 & 0 & 1 \\
\hline jinshui & 0.549 & 0.498 & 0 & 1 \\
\hline
\end{tabular}

There were a few interesting findings. The mean value of gender was 0.21 , indicating that more women participated in the survey. The average age of the respondents in the questionnaire was 50.64 . During the survey process, the research team found that the age of urban household residents who cook and eat at home was on the high side, since an increasing number of young people prefer to eat out or order takeout. The data showed that $48.4 \%$ of the respondents had farming experience.

\subsection{Empirical Results}

There were 273 urban households surveyed in this study, of which 83 households' food waste amount was not zero. The empirical results of Tobit model are presented in Table 7. The results show that urban household consumer perception had a significant effect on food waste behavior. The higher urban household consumer perception positive index, the smaller the amount of food waste per capita per meal, and the higher urban household consumer perception negative index, the greater the amount of food waste per capita per meal. 
Table 7. Empirical analysis results of the Tobit model.

\begin{tabular}{cccccc}
\hline Variable Name & Coef. & & $\begin{array}{c}\text { Std. } \\
\text { Err. }\end{array}$ & $\mathbf{t}$ & dy/dx \\
\hline positive index & -1.675 & $* * *$ & 0.622 & -2.69 & -0.443 \\
negative index & 1.266 & $* *$ & 0.520 & 2.43 & 0.335 \\
gender & -5.063 & & 6.764 & -0.750 & -1.338 \\
age & -0.006 & & 0.306 & -0.020 & -0.001 \\
marriage & & & & & \\
married & -11.846 & & 14.728 & -0.800 & -3.948 \\
divorce & -4.646 & & 23.923 & -0.190 & -1.740 \\
widowed & -26.114 & & 20.920 & -1.250 & -6.818 \\
edu & 0.120 & & 2.783 & 0.040 & 0.032 \\
farmer & 8.741 & & 5.498 & 1.590 & 2.310 \\
employ & & & & & \\
full-time job & 0.799 & & 9.315 & 0.090 & 0.196 \\
part-time job & -7.563 & & 17.671 & -0.430 & -1.560 \\
unemployed & 1.029 & & 16.087 & 0.060 & 0.253 \\
retirement & 3.091 & & 10.186 & 0.300 & 0.793 \\
housework & 33.049 & $*$ & 17.756 & 1.860 & 14.236 \\
odd jobs & 8.293 & & 13.844 & 0.600 & 2.357 \\
other & 0.755 & & 2.934 & 0.260 & 0.200 \\
animal & -17.002 & $*$ & 9.406 & -1.810 & -4.493 \\
cooker & -5.964 & & 6.552 & -0.910 & -1.576 \\
info_fre & 0.082 & & 2.303 & 0.040 & 0.022 \\
refri_num & 0.003 & & 6.787 & 0.000 & 0.001 \\
struct & -6.683 & & 4.249 & -1.570 & -1.766 \\
count_p & & & & & \\
erqi & 10.527 & & 9.175 & 1.150 & 3.179 \\
jinshui & -3.052 & & 8.838 & -0.350 & -0.706 \\
_cons & 31.348 & & 43.774 & 0.720 & \\
\hline
\end{tabular}

Note: ${ }^{* * *},{ }^{* *}$ and ${ }^{*}$ denote statistical significance at the $1 \%, 5 \%$ and $10 \%$ levels, respectively.

Food waste behavior of urban households was not only affected by consumer perception, but also by other factors. For instance, food waste behavior in urban households was also affected by the employment status of the respondents. The food waste per capita per meal of an urban household with a full-time employment status was $8.35 \mathrm{~g}$. For a household with part-time employment status, the waste was $6.15 \mathrm{~g}$, and for unemployed households, food waste was $5.10 \mathrm{~g}$. Retired households wasted $3.10 \mathrm{~g}$ of food, while homemaker households wasted $3.41 \mathrm{~g}$, and those performing odd jobs wasted $6.07 \mathrm{~g}$. Urban households' food waste with an employment status of other was $1.88 \mathrm{~g}$. Further, the food waste of urban households with pets was significantly lower than those without pets.

To test the robustness of the results, this study used the food waste frequency of urban households eating at home instead of the amount of food waste per capita per meal as the dependent variable. Since the frequency of food waste eating at home for urban households was an integer value that is not less than 0 , a counting model was used for estimation. The empirical results of the counting model are shown in Table 8, highlighting that consumer perception still had a significant effect on food waste behavior in urban households. Therefore, the original conclusions were deemed robust. 
Table 8. Empirical analysis results of the counting model.

\begin{tabular}{cccccc}
\hline Variable Name & Coef. & & Std. Err. & $\mathbf{t}$ & $\mathbf{d y} / \mathbf{d x}$ \\
\hline positive index & -0.042 & $* *$ & 0.021 & -1.99 & -0.022 \\
negative index & 0.069 & $* * *$ & 0.018 & 3.78 & 0.036 \\
gender & -0.281 & & 0.219 & -1.28 & -0.147 \\
age & -0.005 & & 0.011 & -0.44 & -0.002 \\
marriage & & & & & \\
married & 0.731 & & 0.744 & 0.98 & 0.277 \\
divorce & 1.776 & $* *$ & 0.878 & 2.02 & 1.265 \\
widowed & -0.502 & & 1.050 & -0.48 & -0.102 \\
edu & -0.050 & & 0.103 & -0.49 & -0.026 \\
farmer & 0.746 & $* * *$ & 0.208 & 3.59 & 0.391 \\
employ & & & & & \\
full-time job & -0.344 & & 0.348 & -0.99 & -0.133 \\
part-time job & 0.649 & & 0.459 & 1.41 & 0.419 \\
unemployed & 0.456 & & 0.497 & 0.92 & 0.265 \\
retirement & 0.292 & & 0.375 & 0.78 & 0.156 \\
housework & 1.790 & $* * *$ & 0.457 & 3.92 & 2.291 \\
odd jobs & 0.354 & & 0.442 & 0.8 & 0.195 \\
other & 0.232 & $* *$ & 0.093 & 2.51 & 0.122 \\
animal & -0.639 & $*$ & 0.371 & -1.72 & -0.335 \\
cooker & -0.542 & $* *$ & 0.222 & -2.44 & -0.284 \\
info_fre & 0.043 & & 0.083 & 0.52 & 0.023 \\
refri_num & -0.148 & & 0.222 & -0.67 & -0.077 \\
struct & -0.093 & & 0.149 & -0.62 & -0.049 \\
count_p & & & & & \\
erqi & 0.776 & $* *$ & 0.371 & 2.09 & 0.364 \\
jinshui & 0.408 & & 0.367 & 1.11 & 0.156 \\
_cons & -2.215 & & 1.626 & -1.36 & \\
\hline Note: *****and *denote statistical significance at the $1 \%, 5 \%$ and $10 \%$ levels, respectively. \\
(*) & & & & &
\end{tabular}

\section{Discussion}

The amount of food waste per capita per meal of urban households eating at home is $5.54 \mathrm{~g}$, which is lower than that found in middle schools' [34], university schools' [35], and restaurants' food waste in China [36]. This discrepancy may be attributable to the change in dining environment or place. What we study is eating at home, while eating in schools and restaurants is categorized as dining out. When eating at home or dining out, people may be in different psychological states, which results in different food waste behaviors. In the process of dining out, consumers may also be unfamiliar with the dining environment. They may not fully anticipate the served quantities of the ordered dishes and may be unaware of the quality of the food, resulting in asymmetric information and more food waste. In the process of eating at home, due to a thorough understanding of the taste and amount of meals eaten by family members, households can avoid food waste in this respect.

In our study, we find several interesting points that deserve our attention. First, in the face-to-face interviews conducted with household members, we find that consumer perception related to food waste varies from person to person and different households have different food waste behaviors. Second, due to the lack of relevant food storage knowledge, urban households sometimes have poor food preservation methods, resulting in unnecessary food waste. Third, when urban households have guests, they tend to prepare more food than necessary to entertain the guests in the name of hospitality and "face culture" in China, especially as it is more difficult to grasp the tastes and meals of visitors, which results in greater food waste. Fourth, most urban household residents report one major cause for food waste as the leftovers being too less to be stored and eaten at a later time. Finally, some household members are unable to reuse leftovers effectively and some foods are less likely to be reused even when stored. 
The findings of the study provide useful suggestions for reducing household food waste. It is found that when consumers are conscious of reducing food waste, they will do their best to reduce food waste. In other words, individuals who have a higher intention to reduce food waste have lower levels of food waste, which is consistent with previous literature [37]. There are many factors that affect consumers' food waste behavior. In order to reduce food waste, we need to intervene in these factors to encourage people to reduce food waste. Among these measures to reduce food waste, we think it is an easy and low-cost way to interfere with consumer perception. Improving consumers' perception of the importance of reducing food waste, such as through media promotion or through organizing events will contribute to the sustainability of food system.

The food waste behavior of urban households eating at home may be influenced by other information and factors, such as the psychological state of households when eating, which requires further analysis. In the future, additional and in-depth research is necessary to identify consumer food waste behavior. Further urban-level research and a larger sample group are needed. This study uses primary food waste survey data on households eating at home in Zhengzhou, and obtaining additional research data from other cities is imperative.

There is a growing body literature on food waste. However, most existing studies are mainly focused on descriptive statistical analysis, while fewer empirical models are used for analysis. Most studies also relied on the secondary data, while a handful of studies are based on first-hand data that are obtained mainly by using self-reporting method. We believe that the amount of food waste calculated by this method appears to be overestimate or underestimate. In our analysis, we quantified food waste by weighing method and converted the wasted food into raw food materials, which provides a high resolution of insights on a specific food category. The food waste data are estimated more accurately by weighing method.

\section{Conclusions}

The results show that consumer perception affects urban household food waste behavior significantly and also demonstrate the relevance of the theoretical framework. The food waste behaviors of urban households are not only affected by consumer perception, but also by other factors such as the employment status of respondents. Further, the food waste behaviors of urban households who have pets are significantly different from food waste behaviors of urban household with no pets. Food waste of urban households with no pets is lower than urban households who have pets. To test the robustness of the results, we substituted the average amount of food waste per capita per meal with the frequency of food waste eating at home in urban households. Counting model regression results show that consumer perception still has a significant impact on food waste behaviors in urban households. Therefore, the original conclusions are robust.

In addition, paying attention to the effect of consumer perception on household food waste behavior is important for exploring possible measures to reduce food waste. Our results confirm the effect of consumer perception on household food waste behavior. When proposing reduction measures of food waste, the results should be taken into account in order to reduce food waste at the individual consumer's level. Therefore, it needs the participation and actions of consumers to reduce food waste. In other words, to reduce food waste at the consumer segment, we need to encourage consumers to form a joint effort to change consumer perception about food waste.

Author Contributions: Data curation, P.Z. and D.Z.; funding acquisition, D.Z.; investigation, P.Z. and D.Z.; methodology, P.Z.; resources, S.C.; supervision, S.C.; writing-original draft, P.Z.; writing-review and editing, D.Z. All authors have read and agreed to the published version of the manuscript.

Funding: This study was supported by the National Natural Science Foundation of China (No. 41601602, 71673272).

Acknowledgments: We deeply appreciate the cooperation of researchers from the Institute of Geographical Sciences and Natural Resources Research, Chinese Academy of Sciences, student volunteers from China Agricultural University, Beijing Institute of Technology, Zhengzhou University, Henan Agricultural University, Henan University of Animal Husbandry and Economy, Shaanxi University of Science and Technology, and Zhengzhou Institute of Finance and Economics, and all interviewed questionnaire respondents in our 
field survey. We especially appreciate Junfei Bai from the College of Economics and Management in China Agricultural University for his suggestions and contributions to this study.

Conflicts of Interest: The authors declare no conflict of interest.

\section{References}

1. Gustavsson, J.; Cederberg, C.; Sonesson, U.; van-Otterdijk, R.; Meybeck, A. Global Food Losses and Food Waste: Extent, Causes and Prevention; FAO: Rome, Italy, 2011.

2. Thyberg, K.L.; Tonjes, D.J.; Gurevitch, J. Quantification of Food Waste Disposal in the United States: A Meta-Analysis. Environ. Sci. Technol. 2015, 49, 13946-13953. [CrossRef]

3. Beretta, C.; Stoessel, F.; Baier, U.; Hellweg, S. Quantifying food losses and the potential for reduction in Switzerland. Waste Manag. 2013, 33, 764-773. [CrossRef]

4. Silvennoinen, K.; Katajajuuri, J.M.; Hartikainen, H.; Heikkilä, L.; Reinikainen, A. Food waste volume and composition in Finnish households. Br. Food J. 2014, 116, 1058-1068. [CrossRef]

5. Schmidt, K. Explaining and promoting household food waste-prevention by an environment psychological based intervention study. Resour. Conserv. Recycl. 2016, 111, 53-66. [CrossRef]

6. Gracia, A.; Gómez, M.I. Food Sustainability and Waste Reduction in Spain: Consumer Preferences for Local, Suboptimal, And/ Or Unwashed Fresh Food Products. Sustainability 2020, 12, 4148. [CrossRef]

7. Zhang, P.P.; Bai, J.F.; Cheng, S.K.; Liu, X.J. Does Information Intervention Affect Food Waste?-Randomized Controlled Trials in Catering Industry. J. Nat. Resour. 2018, 33, 1439-1450.

8. Zhang, P.P.; Wang, L.E.; Bai, J.F.; Liu, X.J.; Cheng, S.K.; Fu, S.P. The food waste behavior of catering consumers from a tourism perspective. Resour. Sci. 2018, 40, 1186-1195.

9. Hu, Y.; Zhou, Y.H.; Han, Y.J.; Xu, R.Z. Resources and Economic Effects Analysis of Reducing Food Waste. China Popul. Resour. Environ. 2013, 23, 150-155.

10. WWF; IGSNRR, CAS. Food Waste Report in Chinese Cities; WWF: Beijing, China, 2018.

11. Cuéllar, A.D.; Webber, M.E. Wasted food, wasted energy: The embedded energy in food waste in the United States. Environ. Sci. Technol. 2010, 44, 6464-6469. [CrossRef]

12. Liu, J.G.; Lundqvist, J.; Weinberg, J.; Gustafsson, J. Food losses and waste in China and their implication for water and land. Environ. Sci. Technol. 2013, 47, 10137-10144. [CrossRef]

13. Venkat, K. The climate change and economic impacts of food waste in the United States. Int. J. Food Syst. Dyn. 2011, 2, 431-446.

14. Cheng, S.K.; Gao, L.W.; Xu, Z.R.; Tang, C.C.; Wang, L.G.; DhrubaBijaya, G.C. Food waste in catering industry and its impacts on resources and environment in China. China Soft Sci. 2012, 7, 106-114.

15. Song, G.B.; Li, M.J.; Semakula, H.M.; Zhang, S.S. Food consumption and waste and the embedded carbon, water and ecological footprints of households in China. Sci. Total Environ. 2015, 529, 191-197. [CrossRef] [PubMed]

16. Zhang, D.; Cheng, S.K.; Gao, L.W.; Cao, X.C.; Liu, X.J.; Liu, Y.; Bai, J.F.; Yu, W. Ecological footprint of catering industry food waste in Beijing. Resour. Sci. 2016, 38, 10-18.

17. Katajajuuri, J.M.; Silvennoinen, K.; Hartikainen, H.; Heikkilä, L.; Reinikainen, A. Food waste in the Finnish food chain. J. Clean. Prod. 2014, 73, 322-329. [CrossRef]

18. FAO; IFAD; UNICEF; WFP; WHO. The State of Food Security and Nutrition in the World: Safeguarding against Economic Slowdowns and Downturns; FAO: Rome, Italy, 2019.

19. Lipinski, B.; Hanson, C.; Lomax, J.; Kitinoja, L.; Waite, R.; Searchinger, T. Installment 2 of "Creating a Sustainable Food Future": Reducing Food Loss and Waste; World Resources Institute: Washington, DC, USA, 2013.

20. Bilska, B.; Tomaszewska, M.; Krajewska-K, D. Analysis of the Behaviors of Polish Consumers in Relation to Food Waste. Sustainability 2020, 12, 304. [CrossRef]

21. Kasza, G.; Dorkó, A.; Kunszabó, A.; Szakos, D. Quantification of Household Food Waste in Hungary: A Replication Study Using the FUSIONS Methodology. Sustainability 2020, 12, 3069. [CrossRef]

22. Aschemann-Witzel, J.; Giménez, A.; Ares, G. Household food waste in an emerging country and the reasons why: Consumer's own accounts and how it differs for target groups. Resour. Conserv. Recycl. 2019, 145, 332-338. [CrossRef]

23. Herzberg, R.; Schmidt, T.G.; Schneider, F. Characteristics and Determinants of Domestic Food Waste: A Representative Diary Study across Germany. Sustainability 2020, 12, 4702. [CrossRef] 
24. Fami, H.S.; Aramyan, L.H.; Sijtsema, S.J.; Alambaigi, A. Determinants of household food waste behavior in Tehrancity: A structural model. Resour. Conserv. Recycl. 2019, 143, 154-166. [CrossRef]

25. Graham-Rowe, E.; Jessop, D.C.; Sparks, P. Predicting household food waste reduction using an extended theory of planned behaviour. Resour. Conserv. Recycl. 2015, 101, 194-202. [CrossRef]

26. Lebersorger, S.; Schneider, F. Discussion on the methodology for determining food waste in household waste composition studies. Waste Manag. 2011, 31, 1924-1933. [CrossRef] [PubMed]

27. Parizeau, K.; von-Massow, M.; Martin, R. Household-level dynamics of food waste production and related beliefs, attitudes, and behaviours in Guelph, Ontario. Waste Manag. 2015, 35, 207-217. [CrossRef] [PubMed]

28. Jörissen, J.; Priefer, C.; Bräutigam, K.B. Food waste generation at household level: Results of a survey among employees of two European research centers in Italy and Germany. Sustainability 2015, 7, 2695-2715. [CrossRef]

29. Annunziata, A.; Agovino, M.; Ferraro, A.; Mariani, A. Household Food Waste: A Case Study in Southern Italy. Sustainability 2020, 12, 1495. [CrossRef]

30. Soma, T.; Li, B.; Maclaren, V. Food Waste Reduction: A Test of Three Consumer Awareness Interventions. Sustainability 2020, 12, 907. [CrossRef]

31. Fanelli, R.M. Using Causal Maps to Analyse the Major Root Causes of Household Food Waste: Results of a Survey among People from Central and Southern Italy. Sustainability 2019, 11, 1183. [CrossRef]

32. Xue, L.; Liu, G.; Parfitt, J.; Liu, X.J.; Van Herpen, E.; Stenmarck, Å.; O'Connor, C.; Östergren, K.; Cheng, S.K. Missing food, missing data? A critical review of global food losses and food waste data. Environ. Sci. Technol. 2017, 51, 6618-6633. [CrossRef]

33. Becker, G.S. A Theory on the Allocation of Time. Econ. J. 1965, 75, 493-517. [CrossRef]

34. Liu, Y.; Cheng, S.K.; Liu, X.J.; Cao, X.C.; Xue, L.; Liu, G. Plate Waste in School Lunch Programs in Beijing, China. Sustainability 2016, 8, 1288. [CrossRef]

35. Wu, Y.L.; Tian, X.; Li, X.R.; Yuan, H.M.; Liu, G. Characteristics, influencing factors, and environmental effects of plate waste at university canteens in Beijing. Resour. Conserv. Recycl. 2019, 149, 151-159. [CrossRef]

36. Wang, L.E.; Liu, G.; Liu, X.J.; Liu, Y.; Gao, J.; Zhou, B.; Gao, S.; Cheng, S.K. The weight of unfinished plate: A survey based characterization of restaurant food waste in Chinese cities. Waste Manag. 2017, 66, 3-12. [CrossRef] [PubMed]

37. Barone, A.M.; Grappi, S.; Romani, S. "The road to food waste is paved with good intentions": When consumers' goals inhibit the minimization of household food waste. Resour. Conserv. Recycl. 2019, 149, 97-105. [CrossRef] 